\title{
COMO ALGUÉM PODE TORNAR-SE PSICANALISTA? ${ }^{\star}$
}

\author{
Taiane Mara De Filippo ${ }^{\star \star}$
}

\begin{abstract}
Resumo
Partindo de uma análise epistemológica acerca da psicanálise, este estudo teórico pretende abordar o tema sobre a cientificidade da psicanálise e sua conseqüencia imediata para a formação de psicanalistas. Este estudo é uma síntese do terceiro capitulo, bem como de parte das considerações finais da dissertação de mestrado intitulada: As aberturas, o meio jogo e os finais nas Recomendações Técnicas de Freud (1911-1915). Foi, portanto, possivel apontar que havia uma exigência freudiana da psicanálise como ciência. Assim, o aparecimento de um novo profissional, divorciado do saber médico, era também reivindicado. Deste modo, é aceitável concluir que uma formação inicial em psicologia é necessária, embora não seja suficiente, para a formação de um psicanalista que trabalhe na clínica a partir dos ensinamentos de Freud.
\end{abstract}

Palavras-chave: epistemologia; psicologia; psicanálise; Freud; formação profissional.

\section{HOW CAN SOMEONE BECOME A PSYCHOANALYST?}

\begin{abstract}
From an epistemological analysis of psychoanalysis, this theoretical study aims to approach the theme of psychoanalysis' scientificity and its immediate consequence to psychoanalysts' formation. This study is an abstract of the third chapter, as well as parties of the final considerations of the master's dissertation called: The openings, the middlegame and endgame in the Freud's Technical Recommendations (1911-1915): and epistemological analysis. Therefore, it was possible to indicate a Freudian demand for psychoanalysis as a science. Then, the appearance of a new professional, divorced from medical knowledge, was also vindicated. This way, it is acceptable to conclude that an initial formation in psychology is necessary, although not sufficient, to the formation of a psychoanalyst who works with the clinical approach, according to Freud's teachings.
\end{abstract}

Keywords: Epistemology; Psychology; Psychoanalysis; Freud; professional formation.

^ Pesquisa de mestrado apoiada pela Bolsa de Demanda Social/CAPES.

$\star \star$ Mestre em Ensino, Filosofia e História das Ciências - Universidade Federal da Bahia/ Universidade Estadual de Feira de Santana. Avenidas Tancredo Neves, 2421 - Centro Empresarial Redenção, sala 204. Caminho das Árvores, Salvador, Bahia - CEP: 41.820-020. E-mail: taianedefilippo@terra.com.br 
Neste artigo apresentaremos as conclusões que, de um modo geral, pudemos encontrar neste caminho de uma epistemologia da psicanálise. Pretendemos compartilhar a descoberta de uma exigência, presente no texto freudiano, da psicanálise como ciência e, a partir desta constatação, apresentar as implicações para a formação de analistas que foi possível desprender desta pesquisa de mestrado ${ }^{1}$.

Devemos esclarecer que, ao propor uma análise filosófica do texto freudiano, extraímos de nossa pesquisa qualquer pretensão de reduzir-lo a uma doutrina filosófica, não pretendíamos encontrar um Freud humeano, kantiano, marxista, hegeliano, platônico etc., como sabemos ser o propósito de outras pesquisas em epistemologia da psicanálise. Quisemos mostrar um Freud freudiano. Mas, também, não fizemos uma pesquisa em teoria psicanalítica, portanto os avanços da teoria presentes em autores posteriores a Freud ficaram de fora desta análise, como, por exemplo, as contribuições ou novas formulações de Lacan. Desta forma, reivindicamos o direito de encerrar em Freud esta leitura apoiando nosso argumento em Mezan e na sua proposta de como ler Freud (MEZAN, 1982).

Ainda uma ressalva, que serve como um alerta e uma desculpa inicial: salientamos que esta pesquisa ao caminhar numa fronteira possa trazer, em algumas passagens, um vocabulário aparentemente estranho ou inadequado, ora para a filosofia, ora para a psicanálise e ou mesmo para as ciências. Esta advertência tem o único propósito de evidenciar e ultrapassar dificuldades inerentes a uma pesquisa de fronteira, como esta entre ciência, filosofia e psicanálise.

Antes de passarmos para a questão primeira, evidenciada no título Como alguém pode tornar-se psicanalista?, faremos uma pequena introdução ao tema da formação que está inteiramente relacionado à questão sobre a cientificidade da psicanálise, tema da dissertação no mestrado.

Devemos iniciar, então, com uma citação de Freud, de 1925, em seu "Um estudo autobiográfico", em que ele afirma que:

Do ponto de vista prático, alguns analistas atribuíram a tarefa de fazer com que a psicanálise seja reconhecida nas universidades e incluída no currículo médico, ao passo que outros se contentam em permanecer fora dessas instituições, não permitindo que a psicanálise seja menos importante no campo da educação de que no da medicina. Ocorre de quando em quando que um profissional da análise verifique estar isolado em uma tentativa de enfatizar algum ponto único dos achados ou pontos de vista da psicanálise, à custa de todos os demais. Não obstante, a impressão total é satisfatória - de trabalho científico sério executado em alto nível (FREUD, 1987b [1925], p. 92).

Bem, como vimos, em 1925, Freud vangloriava-se de que a psicanálise era um trabalho científico sério. A partir disto é possível completar, com o apoio de outras passagens disseminadas pela obra de Freud, dizendo que fazer da psicanálise uma ciência é uma exigência presente em todo o projeto freudiano. Mas 
vale a ressalva, de que para Freud era sob o molde de uma ciência natural - como a física ou a química - que a psicanálise devia ser pensada. Vale ainda dizer que o nome psicanálise, criado por Freud, é inspirado na química analítica, que, segundo Isabelle Stengers (1992), "era a ciência rainha" na época dele. Apenas para enfatizar o quanto a química analítica criada por Lavoisier, ainda no século XVIII, foi capaz de inspirar todas as esferas da produção humana, fomos buscar na literatura fantástica de Edgard Alan Poe (2001, p. 65) a seguinte descrição:

As Faculdades do espírito, denominadas analíticas são, em si mesmas, bem pouco suscetíveis de análise. Apreciamolas somente em seus efeitos. O que delas sabemos, entre outras coisas, é que são sempre, para quem as possui em grau extraordinário, fonte do mais intenso prazer. Da mesma forma que o homem forte se rejubila com suas aptidões físicas, deleitando-se com os exercícios que põem em atividade seus músculos, exulta o analista com essa atividade espiritual, cuja função é destrinçar enredos. Acha prazer até mesmo nas circunstâncias mais triviais, desde que ponham em jogo seu talento. Adora os enigmas, as adivinhas, os hieróglifos, exibindo nas soluções de todos eles um poder de acuidade, que, para o vulgo, toma o aspecto de coisa sobrenatural. Seus resultados, alcançados apenas pela própria alma e essência do método, têm, na verdade, ares de intuição.

É o trecho inicial do conto Os crimes da Rua Morgue, de 1841, de Poe, ou seja, de alguns anos antes de Freud batizar sua jovem ciência com o nome de psicanálise, em 1896.

Assim, retornando ao nosso tema, citamos Stengers (1992, p. 35) com sua bela imagem sobre o fazer científico:

Eu considero que as ciências ditas modernas, nascidas há perto de quatro séculos, constituem uma aventura singular, profundamente original, apaixonante - e que me apaixona pelo que ela nos podem ensinar a uma só vez sobre o mundo e sobre os homens que as levam. Eu desejaria assinalar que, quando uma ou outra ciência nos ensinou alguma coisa de que nós não suspeitávamos em relação ao mundo, ela nunca nos decepcionou. Nunca, desde a descoberta da força de atração de Newton até a inimaginável selva de neurônios que habita nossa caixa craniana, ela não empobreceu nossa imaginação, mas sem cessar nos relançou sobre caminhos novos. ${ }^{2}$

Se somarmos esta imagem de ciência trazida por Stengers à hipótese da psicanálise fundada sob a moldura da modernidade, é possível afirmar que também a psicanálise deve ser reconhecida, a partir da definição desta autora, como uma ciência. Pois como nos bem disse Freud, a psicanálise prescinde de uma Weltanschauung, porque ao pertencer ao campo das ciências deve submeter-se a uma visão de mundo científica e não mística ou, ainda, religiosa. 
Assim, submetendo este adjetivo ciência a novas concepções do termo para dar conta desta jovem ciência, é possível identificar condições de possibilidade para a psicanálise como possível ciência.

Sabemos o quanto estas últimas considerações podem ir de encontro ao que os psicanalistas têm freqüentemente aludido ao tomar para si questões sobre a cientificidade da psicanálise. Assim, usamos Stengers mais uma vez como inspiração para justificar nosso posicionamento um tanto ortodoxo na psicanálise. Ela adverte:

Ninguém é obrigado a se definir como científico. Eu me endereço, portanto, aos psicanalistas que entendem manter as pretensões da psicanálise freudiana, ou se interrogam sobre o tipo de ciência que poderia decorrer do "fracasso" de 1937, como a psicanálise decorreu do "fracasso" de outras técnicas (STENGERS, 1992, p. 67).

Quando ela afirma que suas palavras têm endereço apropriado, também para nós é disso que se trata. E quando fala do fracasso de 1937, Stengers referese à pergunta que Freud faz acerca da eficácia da psicanálise, no texto "Análise terminável e interminável".

Seguimos, nesta pesquisa, a letra freudiana a partir de uma analogia com o jogo de xadrez, aparentemente, descomprometida com o tema da cientificidade, mas inteiramente comprometida com a questão da formação de analistas. Na analogia, Freud diz o seguinte:

Quem desejar aprender nos livros o nobre jogo do xadrez logo descobrirá que somente as aberturas e os finais permitem uma descrição sistemática exaustiva, enquanto a infinita variedade de movimentos após a abertura desafia uma tal descrição. Apenas o estudo diligente de partidas dos mestres pode preencher a lacuna na instrução. As regras que podemos oferecer para o exercício do tratamento psicanalítico estão sujeitas a limitações parecidas (FREUD, 1996, p. 153).

E, a partir desta analogia, foi possível analisar os artigos sobre a técnica, escritos entre 1911 e 1915, em que: 1) verificamos o que há de essencial nos procedimentos de "abertura" de uma análise; 2) reconhecemos a necessidade do "estudo diligente das partidas dos mestres" para preencher as lacunas presentes na "arte do meio jogo", que é a cena analítica; e com 3) o "final” de análise compreendemos que, ao fundar uma nova ciência, era de um novo lugar, de outro discurso que Freud falava. Retomando as palavras de Stengers (1992, p. 65), temos que "a cena analítica, desprovida do poder que Freud lhe havia atribuído, perde seu sentido, que ela não seja o lugar que Freud havia acreditado construir, não significa evidentemente que nada teve lugar". É sobre este fracasso, segundo esta autora, que devemos prosseguir, desbravando novos horizontes, afinal, não é disso que se trata quando fazemos ciência? 
Em um texto ainda inédito do psicanalista e professor Renato Mezan, intitulado Que tipo de ciência é, afinal, a Psicanálise?, este autor faz um percurso apontando o que afirmamos anteriormente sobre o estatuto de ciência necessário à psicanálise em Freud. Mezan encerra sua argumentação dizendo o seguinte:

O objeto da Psicanálise pertence ao campo do humano, seus métodos são similares aos das ciências humanas, seu perfil epistemológico tem muito de comum com o de outras disciplinas humanas: faz sentido concluir que ela é uma ciência humana, n'en déplaise ao Herr Professor. Como respondeu Dona Sara ao seu filho, o pequeno Isaac, que lhe perguntava por que os lockshen (fios de macarrão) se chamam lockshen: "Mas querido, se eles têm gosto de lockshen, parecem lockshen, vêm em pacotes como os lockshen - por que não iriam se chamar lockshen?" (MEZAN, 2006, p. 475).

A piada vale para dar o devido lugar às argumentações que formulamos aqui. O terreno é árido, então, e o humor serve para aplacar nossas dificuldades. Ainda temos o que investigar; os problemas sobre a formação de analistas inspiram cuidados.

Entretanto, nosso objetivo, ao empreender tal discussão, foi tentar provar que a psicanálise, sendo reconhecida como disciplina científica, deve ser considerada como uma escola ou doutrina teórica da ciência psicológica. A ciência psicológica, ou, as psicologias contemplam diferentes (e divergentes!) matrizes teóricas de fundamentação filosófica. Deste modo, pensamos que historicamente a ruptura das psicologias com o saber médico/fisiológico seria um forte argumento para inserir a psicanálise junto à ciência psicológica.

E de que modo flagramos esta ruptura da psicanálise com o saber médico/ fisiológico? Devemos recorrer ao dispositivo técnico de fazer o paciente deitar-se no divã. No início, para Freud, este dispositivo técnico era apenas um resquício da antiga técnica hipnótica e, também, uma forma de se manter confortavelmente longe dos olhos de seus pacientes durante a jornada diária de atendimentos. ${ }^{3} \mathrm{Sa}$ bemos ainda que, enquanto um dispositivo técnico, deitar-se no divã acaba obedecendo, sobremaneira, à regra fundamental e àquela frieza cirúrgica que deve acompanhá-la: "não quero que as expressões de meu rosto forneçam material para interpretações do paciente ou influenciem o que ele tem a comunicar" (FREUD, 1996, p. 163). Acompanhando, ainda, suas "Recomendações...", Freud encerra seu texto oferecendo ao analista argumentos para a manutenção desta frieza cirúrgica. A lição resume-se assim: "O médico deve ser opaco para o analisando, e, tal como um espelho, não mostrar senão o que lhe é mostrado" (FREUD, 1999, p. 163). E, deste modo, ele pode livrar a cena analítica das resistências iniciais catalogadas nestes dispositivos técnicos, promovendo o que Freud chama de verdadeira psicanálise, uma vez que, segundo Quinet (1991, p. 42): “[...] a indicação do divã pontua o fim dessas entrevistas, marcando a entrada em análise". 
Mas, de fato, o que deve ser destacado neste dispositivo é a definitiva cisão entre a psicanálise e a medicina, o olho clínico da tradição médica - hoje em dia, cada vez mais especializado em tomografias e ressonâncias computadorizadas - foi definitivamente substituído pela escuta clínica na psicanálise. ${ }^{4}$

Portanto, a ruptura com o saber médico e a instauração deste novo campo de saber, que hoje tentamos definir como sendo o lugar da subjetividade, é uma tentativa da psicologia de estabelecer uma unidade entre suas escolas. Mas, como nos adverte Figueiredo (1991, p. 206):

A única unificação possível se daria, assim, fora do campo da psicologia, no plano de uma crítica histórica e epistemológica à psicologia, como ciência independente, vale dizer, na negação deste projeto, trazendo de volta a psicologia para junto das ciências sociais e da filosofia. Nesta unificação, contudo, as divergências e conflitos não seriam anulados, mas esclarecidos e conservados .

Invocamos, então, duas perguntas que ainda poderiam suscitar esta distinção entre a psicanálise e as psicologias: 1) podemos dizer que à psicanálise caberia o inconsciente como objeto, enquanto para a psicologia - ou as psicologias - restaria a consciência? 2) sabemos que nenhum dos grandes nomes da psicanálise, como Freud, Klein ou Lacan, era psicólogo, então, por que uma formação em psicologia seria hoje necessária?

Para a primeira questão também pensamos encontrar argumento favorável à nossa tese principal. Sim, é verdade que algumas escolas psicológicas não admitem o inconsciente como objeto de estudo, aliás, trata-se de um movimento que ultrapassa nossa ciência e invade o campo da epistemologia. ${ }^{5}$ Mas a psicanálise não pode restringir seu campo à novidade de sua teoria, pois admitir o inconsciente não é de nenhum modo retirar a consciência de seu âmbito teórico. Afinal, o inconsciente, ainda em Freud, só é dado a conhecer através de suas manifestações na consciência, através dela. Por outro lado, se há entre os psicólogos não-analistas uma certa dificuldade em admitir a "existência" do inconsciente, para eles, temos em um de seus últimos textos, de 1938, as seguintes palavras de Freud (1987d [1938], p. 184):

Assim também estará inteiramente de acordo com nossas expectativas que os conceitos e princípios básicos da nova ciência (pulsão, energia nervosa, etc.) permaneçam por tempo considerável não menos indeterminados que os das ciências mais antigas (força, massa, atração, etc.).

Este, juntamente com muitos outros trechos, foram capazes de mostrar o quanto a exigência freudiana, da psicanálise como ciência, percorre toda a construção teórica de Freud. E, sendo assim, qual a conseqüência imediata ao inserirmos a psicanálise como uma ciência, e mais, como uma ciência psicológica? 
Pensamos com este percurso iniciar uma discussão que parte do campo da epistemologia retornando à questão "Como alguém pode tornar-se psicanalista?", introduzida por Freud em 1912, quando escrevia um de seus textos técnicos.

Admitimos, como no fragmento de Figueiredo (1991) anteriormente citado, que para o estabelecimento criterioso de nossa formação é necessário o percurso pela história e pela filosofia, afinal, é apenas através deste percurso que somos capazes de responder perguntas sobre nossa práxis e nosso lugar na sociedade. E, com a citação do filósofo Georges Canguilhem (1999, p. 26), queremos mostrar o quanto o questionamento filosófico tem a contribuir com nossa ciência e o que fazemos com ela:

Por conseguinte, é de forma muito vulgar que a filosofia interroga a psicologia e diz: para onde ides, para que eu saiba quem sois? Mas o filósofo também pode dirigir-se ao psicólogo sob a forma de um conselho - uma única vez não cria o hábito - e dizer: quando se sai da Sorbonne pela rua Saint-Jacques, pode-se subi-la ou descê-la; quando se sobe, chega-se ao Panteão, o Conservatoire de alguns grandes homens, mas quando se desce, certamente se chega à delegacia de polícia.

Sendo assim, uma possível conclusão desta pesquisa é que para alguém se tornar psicanalista - entendendo que o psicanalista que falamos é aquele com uma atuação clínica - uma formação em psicologia deve ser necessária, embora não seja suficiente. Como também acreditamos que em outras escolas da psicologia a formação generalista, que deve ser priorizada na formação de um psicólogo clínico, não pode ser considerada suficiente para moldar um profissional especialista neste segundo momento da formação.

Deste modo, somos conduzidos à segunda questão, sobre grandes psicanalistas não serem psicólogos formados. Sabemos que na época de Freud, Klein e mesmo Lacan, um curso de formação em psicologia, por conseguinte do profissional de psicologia, ainda não estava instituído - o que, por exemplo, ocorreu apenas em 1941 na Alemanha, e em 1954 no Brasil (PEREIRA, 2007). Não seria possível admitir que a carreira do psicólogo clínico se inicia com os atendimentos clínicos de Freud? Ele mesmo admitiu que uma formação médica não era suficiente para alguém se tornar analista. Se em sua época a "questão da análise leiga" precisou ser discutida, fica evidente, para nós, que era também por um novo profissional que a jovem ciência freudiana demandava.

E assim, encontramos no texto A questão da análise leiga argumentos para falar deste novo profissional e sua necessária formação. Neste texto, Freud (1987c [1926], p. 265) dirá: “[...] ponho ênfase na exigência de que ninguém deve praticar a análise se não tiver adquirido o direito de fazê-lo através de uma formação específica". E segue no texto estabelecendo critérios para esta formação específica. É o que está dito nesta passagem: 
Um esquema de formação para analistas ainda tem de ser criado. Deve ele abranger elementos das ciências mentais, da psicologia, da história da civilização e da sociologia, bem como da anatomia, da biologia e do estudo da evolução. (FREUD, 1987c [1926], p. 286).

Nesta proposta de currículo resumida por Freud, podemos reconhecer uma formação em ciências humanas, mais do que em ciências médicas. E ele conclui, no parágrafo seguinte, o que deve ser o estabelecimento definitivo da psicanálise como uma ciência psicológica demandando este novo profissional divorciado da medicina:

Não terá escapado aos meus leitores que naquilo que afirmei presumi como axiomático algo que é ainda violentamente debatido no exame. Presumi, vale dizer, que a psicanálise não é um ramo especializado da medicina. Não vejo como é possível discutir isso. A psicanálise é uma parte da psicologia; não da psicologia médica no velho sentido, não da psicologia de processos mórbidos, mas simplesmente da psicologia. Certamente não é o todo da psicologia, mas sua subestrutura e talvez mesmo todo o seu alicerce. A possibilidade de sua aplicação a finalidades médicas não nos deve desorientar (FREUD, 1987c [1926], p. 286-287).

Mas esta formação acadêmica e científica de um analista não exclui em absoluto o que Freud afirma em um dos artigos técnicos, Recomendações ao médico que pratica a psicanálise, de 1912, e que serviu de inspiração para o título deste estudo. Ele diz assim: "Anos atrás, dei a seguinte resposta à questão de como alguém pode tornar-se psicanalista: 'Pela análise dos próprios sonhos" (FREUD, 1999, p. 433).

Insistimos de que há uma necessária, mas insuficiente formação em psicologia para amparar a formação de analistas prescrita por Freud nas instituições de psicanálise, como ainda hoje acontece, pois, em 1926, ele já defendia a formação em três instantes afirmando que:

Nesses institutos [de psicanálise] os próprios candidatos são submetidos à análise, recebem instrução teórica mediante conferências sobre todos os assuntos que são importantes para eles, e desfrutam da supervisão de analistas mais velhos e mais experimentados quando lhes é permitido fazer suas primeiras experiências com casos relativamente brandos. (FREUD, 1987c, Vol. XX, p. 258).

A formação em psicologia seria o movimento inicial para o exercício da psicanálise em intenção, do analista na clínica. Acreditamos que as lições em psicologia são fundamentais para o exercício da psicanálise clínica. Falamos especialmente de técnicas e procedimentos apre(e)ndidos em psicologia que não fazem parte desta formação teórica nas instituições de psicanálise. Por exemplo, 
a questão do diagnóstico e do tipo de encaminhamento que se faz necessário para além de uma escuta psicanalítica - perguntamos: será que uma formação inicial em psicologia não daria este suporte mais abrangente do que uma intervenção clínica demanda? Mas também apontamos que a formação de um psicanalista, balizada por Freud através do tripé: formação teórica em institutos especializados, supervisão e análise pessoal, deve servir de modelo para as outras escolas da psicologia que pretendem formar um psicólogo clínico em uma determinada escola. Então, concluímos: a formação do psicólogo clínico se daria na academia, a partir de uma formação generalista e para cada escola, das diferentes teorias que formam a ciência psicológica, haveria institutos especializados que garantiriam a formação deste especialista, por exemplo, em psicanálise, bioenergética, psicodrama e assim por diante.

Podemos concluir que, com o texto de 1937, Freud evidencia os limites de sua técnica. Alertando que a psicanálise está entre aquelas "profissões 'impossíveis' quanto às quais de antemão se pode estar seguro de chegar a resultados insatisfatórios. As outras duas, conhecidas há muito tempo, são a educação e o governo" (FREUD, 1987d [1938], p. 282). Assim, nosso autor garante aos analistas sucessores que há dificuldades com as quais ele vai lidar em seu fazer diário. Depois desta investigação, foi possível ampliar nossos argumentos sobre a necessidade de uma formação adequada que pode minimizar tais dissabores. Assim, queremos deixar evidenciado o quanto fazer psicanálise requer uma postura mais humilde e menos alienada encerrada em uma prática, e nenhum analista pode considerar-se rei na cena analítica se é capaz de aceitar suas próprias limitações.

Aprendemos com Stengers (1992), portanto, que fazer uma psicanálise científica é não nos deixar estagnar, é sabermos, sem cessar, nos "relançar sobre caminhos novos", avançando com as palavras de Freud, mas sem esquecê-las. Deste modo, devemos levar em conta as palavras finais de Freud em seu texto Análise terminável e interminável, de 1937, quando ele diz:

Seria difícil dizer se e quando conseguimos êxito em dominar esse fator [o grande enigma do sexo] num tratamento analítico. Só podemos consolar-nos com a certeza de que demos à pessoa analisada todo o incentivo possível para reexaminar e alterar sua atitude para com ele (FREUD, 1987e [1937], p. 287).

Em uma nota de rodapé, nosso autor nomeia "o grande enigma do sexo" como sendo a castração. E aqui nossa analogia com o jogo do xadrez se junta ao terceiro grande golpe desferido contra a humanidade que a psicanálise veio trazer. Nas palavras de Freud (1987a [1917], p. 336):

[...] a megalomania humana terá sofrido seu terceiro golpe, o mais violento, a partir da pesquisa psicológica da época atual, que procura provar ao eu que ele não é senhor nem mesmo em sua própria casa, devendo, porém, contentarse com escassas informações acerca do que acontece inconscientemente em sua mente. 
Deste modo destituído, o eu rei absoluto de sua razão e consciência é colocado em xeque. Finalizamos com esta imagem do sujeito castrado, verificando mais uma vez a pertinência, em nossa pesquisa, da analogia freudiana em relação ao xadrez. Portanto, para Freud, um final de análise pode ser descrito com este analisando deparando-se com sua castração e sua condição inquestionável de ser finito, de sua própria morte. Da morte de quem um dia pensou-se rei. E assim, trazemos as palavras de Safouan (apud DIDIER-WEIL; WEISS; GRAVAS, 2007, p. 96) para ilustrar o que deve ser o propósito de uma análise:

Se a análise é um processo que não tem um fim, mas uma finalidade, é porque ela permite a transformação da pulsão. É assim que aparece, com essa sublimação, um novo posicionamento subjetivo: nova relação com a cultura, nova relação com o trabalho, que se torna mais eficaz, nova relação na qual o analisando cessa de ser um objeto regressivo para os pais ou cessa, se for pai, de ter com o filho uma relação regressiva.

A imagem também deve valer para analistas e candidatos a analistas.

\section{Notas}

${ }^{1}$ Conferir nota de rodapé na primeira página deste artigo.

${ }^{2}$ Texto original em francês, sem tradução oficial para o português.

${ }^{3}$ Concordamos com Quinet (1991, p. 44-45), quando afirma ser desnecessário "bancar o analista de Freud", tentando interpretar o dispositivo do "divã", através do material inconsciente fornecido em seus próprios sonhos, difundidos ao longo de sua obra. Preferimos a posição de encontrar neste dispositivo, inicialmente fortuito, os fundamentos da teoria a posteriori.

${ }^{4}$ A referência à pulsão escópica aparece, em Freud, enquanto resistência do analisando ao dispositivo. Depende do quanto esta pulsão, tratada por ele de voyeurismo, significa para cada paciente. É Lacan que vai abordar mais largamente o sentido da pulsão escópica para o dispositivo do divã (QUINET, 1991, p. 47-49).

${ }^{5}$ Dois textos serviram de guia para esta questão: 1) Serbena e Rafaelli (2003); 2) Carone (2003).

${ }^{6}$ Fazemos alusão ao texto clássico de Freud (1987c [1926]), A questão da análise leiga, escrito para justificar e apoiar uma formação não-médica para psicanalistas. 


\section{REFERÊNCIAS}

CANGUILHEM, G. Que é a Psicologia? Revista de Ciências Sociais e Humanas, Piracicaba / SP, v. 11, n. 26, p. 11-26, 1999.

CARONE, I. A psicologia tem paradigmas? São Paulo: Casa do Psicólogo/ Fapesp, 2003.

DIDIER-WEIL, A.; WEISS, E.; GRAVAS, F. (Org.). Entrevista com Moustapha Safouan. In: Quartier Lacan: testemunhos. Rio de Janeiro: Companhia de Freud, 2007. p. 81-96.

FIGUEIREDO, L. C. M. Matrizes do pensamento psicológico. Petrópolis: Vozes, 1991.

FREUD, S. Conferência XVIII: fixação em traumas - o Inconsciente (1917). In: . Obras Completas Psicológicas de Sigmund Freud. Rio de Janeiro: Imago, 1987a. Edição Standard Brasileira, v. XXII. p. 323-336.

. Um estudo autobiográfico (1925). In: Obras Completas

Psicológicas de Sigmund Freud. Rio de Janeiro: Imago, 1987b. Edição Standard Brasileira, v. XX. p. 17-92.

A questão da análise leiga (1926). In: - Obras Completas Psicológicas de Sigmund Freud. Rio de Janeiro: Imago, 1987c. Edição Standard Brasileira, v. XX. p. 209-293.

. Esboço de Psicanálise (1938). In: . Obras Completas Psicológicas de Sigmund Freud. Rio de Janeiro: Imago, 1987d. Edição Standard Brasileira, v. XXIII. p. 168-237.

. Análise terminável e interminável (1937). In: . Obras Completas

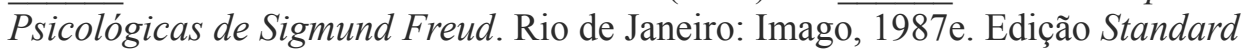
Brasileira, v. XXIII, p. 239-287.

. Sobre o início do tratamento. Jornal de Psicanálise, São Paulo, v.

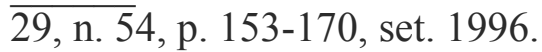

. Recomendações ao médico que pratica a psicanálise. Jornal de Psicanálise, São Paulo, v. 32, n. 58/59, p. 427-436, nov. 1999.

MEZAN, R. Que tipo de ciência é, afinal, a Psicanálise? In: ENCONTRO NACIONAL DE FILOSOFIA DA ANPOF, 12., 2006, Salvador. Atas..., Salvador: [s. n.], 2006. p. 475. 
MEZAN, R. Freud: a trama dos conceitos. São Paulo: Perspectiva, 1982.

PEREIRA, M. E. História da Psicologia: linha do tempo das idéias psicológicas. Disponível em: <www.geocities.com/athens/delphi/6061/ linha3.htm>. Acesso em: 1 jun. 2007. Identificador: LISBR1.1-21680.

POE, E. A. Ficção completa, poesia e ensaios. Rio de Janeiro: Nova Aguilar, 2001.

QUINET, A. As 4+1 condições de análise. 2. ed. Rio de Janeiro: J. Zahar, 1991.

SERBENA C. A.; RAFAELLI R. Psicologia como disciplina científica e discurso sobre a alma: problemas epistemológicos e ideológicos. Psicologia em Estudo, Maringá, v. 8, n. 1, p. 31-37, jan./jun. 2003. Disponível em: <http://www.scielo. br/pdf/pe/v8n1/v8n1a05.pdf>. Acesso em: 12 nov. 2004.

STENGERS, I. La volonté de faire science: à propos de la psychanalyse. Paris, Collection les Empêcheurs de Penser en Rond, 1992.

Recebido em: novembro de 2007 Aceito em: agosto de 2008 